\title{
Correction to: Update \\ on Adverse Effects of HIV \\ Integrase Inhibitors
}

Agnieszka Kolakowska, $M D^{1}$

Anaenza Freire Maresca, $M D^{1}$

Intira Jeannie Collins, $P h D^{2, *}$

Johann Cailhol, MD, $P h D^{1,3}$

\section{Address}

${ }^{1}$ Infectious and Tropical Diseases Department, Avicenne University Hospital, Bobigny, France

${ }^{*}, 2$ MRC Clinical Trials Unit at UCL, Institute of Clinical Trials \& Methodology, 90 High Holborn, 2nd Floor, London, WC1V 6LJ, UK

Email: jeannie.collins@ucl.ac.uk

${ }^{3}$ Infectious and Tropical Diseases Department, Avicenne University Hospital and

Paris 13 University, Bobigny, France

Published online: 4 January 2021

(C) Springer Science+Business Media, LLC, part of Springer Nature 2021

The online version of the original article can be found at https://doi.org/10.1007/s40506-019-00203-7

A correction to this paper has been published: https://doi.org/10.1007/s40506-020-

00245-2

Correction to: Curr Treat Options Infect Dis (2019) 11:372-387

https://doi.org/10.1007/s40506-019-00203-7

The original published version of this paper should be deposited to PMC. In order for the paper to be deposited to $\mathrm{PMC}$, the below tagging for article funding information should be captured in the XML. 
$<$ ArticleFundingInformation $>$

$<$ Fund $>$

$<$ FunderName FundRefID="https://doi.org/10.1007/s40506-019-00203-7">Medical Research Council

$<$ FunderName $>$

$<$ GrantNumber GrantRecipient="Au3" Type="FundRef" $>$ MC_UU_12023/26</GrantNumber $>$

$<$ Fund $>$

$</$ ArticleFundingInformation $>$

The original article has been corrected.

\section{Publisher's Note}

Springer Nature remains neutral with regard to jurisdictional claims in published maps and institutional affiliations. 